\title{
Ilustración y esoterismo en Le Crocodile, de Louis-Claude de Saint-Martin
}

\author{
Enlightenment and Esotericism in Louis-Claude \\ de Saint-Martin's Le Crocodile
}

\author{
María Gloria CALDERÓN XELHUANTZI \\ Facultad de Filosofía y Letras \\ Universidad NACIONAL AuTÓNOMA DE MÉXICO \\ México
}

\begin{abstract}
Resumen
En estas páginas nos interesa comunicar cuatro ideas principales sobre Le Crocodile y su autor, Louis-Claude de Saint-Martin. La primera es definirla como una novela cuyos elementos, incluido el tema iluminista, responde al género de la novela filosófica, característico del siglo XVIII. Segunda, comunicar que, derivado de las ideas iluministas que están presentes en ella, Le Crocodile puede calificarse también como una novela esotérica, debido a que el término esoterismo empezó a utilizarse a finales del siglo XIX para referirse a temas que antes se abordaban como iluminismo. Tercera: informar sobre ideas iluministas que se encuentran presentes en esta novela de Saint-Martin. Cuarta: resaltar el valor satírico de esta novela que evidencia aspectos menos conocidos del Siglo de las Luces, exhibiendo a los poderes de su tiempo (Iglesia, academias, gobiernos, filosofismo) que en pleno siglo XVIII perpetúan los vicios de los que la Ilustración quería liberar a los hombres, y quienes imponían y sojuzgaban otras formas de conocimiento diferentes a las del materialismo promovido por las ciencias.
\end{abstract}

Palabras clave: esoterismo, iluminismo, Ilustración, Louis-Claude de SaintMartin, novela filosófica

\footnotetext{
Abstract

The following pages mean to communicate four main ideas on Louis-Claude de Saint-Martin and his only novel, Le Crocodile. While Louis-Claude de Saint-Martin's piece can be considered as developing esoteric ideas through a philosophical fiction, it also reveals a satiric intention towards academies and other authorities
} 
that consider science as the only valid way to knowledge despite the existence of a worthy tradition of spiritual understanding of the world.

Keywords: esotericism, illuminism, Enlightenment, Louis-Claude de SaintMartin, philosophical fiction

No obstante la importancia que Paul Bénichou concede a Louis-Claude de SaintMartin (1743-1803) como el representante más influyente del iluminismo en la literatura francesa, su obra ha sido poco conocida, incluso a pesar de que los escritores y poetas románticos manifiestan cierto contacto con sus ideas. La historia literaria reconoce su eco en la obra de Lamartine, de Vigny, de Balzac, y del mismo Hugo; sin embargo, poco se conoce de la única obra de ficción de Louis-Claude de Saint-Martin, quien firmaba sus trabajos como el Filósofo desconocido. Su biógrafo, M. Matter (1862) refiere que los círculos académicos y literarios de su tiempo desdeñaron su novela Le Crocodile, considerándola grotesca y obra de un autor extravagante. A pesar de esto, Rüdiger Safranski (2009) considera que Saint-Martin gozó de gran aceptación en Alemania, incluida esta novela, lo cual no es extraño porque el autor estuvo muy cercano a esa nación a través de los contactos con los grupos iluministas y el misticismo de Jakob Böhme. La propuesta de estas páginas es, por lo tanto, presentar el valor de Le Crocodile (1799) y resaltar que, a pesar de la limitada aceptación que logró en su propio país, es un testimonio del agitado clima intelectual y las contradicciones que animaron el Siglo de las Luces. Durante este siglo, a pesar de su interés por promover y defender la emancipación de los hombres, fueron despreciadas y atacadas formas de conocimiento ajenas al materialismo dominante y al monopolio de las ciencias ejercido por las academias. También nos interesa subrayar que Saint-Martin escribe la novela hacia el final de su vida, utilizando un género más propicio para ser leído por lectores inclinados a una visión diferente de la realidad, es decir, alejados del medio académico para el cual el autor ya había escrito bastante (Matter, 1862). Aquí nos interesa dar cuenta tanto del mensaje transcendente como del mensaje satírico de la novela de Saint-Martin, pues en ambos se entreteje también la historia del iluminismo y de sus grupos, especialmente los de la francmasonería.

\section{Una novela filosófica}

Durante el siglo XVIII se encuentra en ciernes un género que adquirió solidez y prestigio hasta el siglo XIX: la novela. Pero la novela que en el siglo XVIII aún no había adquirido valor en la tradición literaria era muy diferente de lo que hoy se considera el género más gustado por los lectores. La gran libertad que la distingue era, en aquel tiempo, un elemento incómodo. Sin embargo, la falta de normativa 
para un género sin credenciales de nobleza permitía abordar en él temas muy variados, desarrollándolos en prosa y en verso, con narración, pero también con diálogos. Así, el largo título de la novela filosófica de Saint-Martin, Le Crocodile, ou la guerre du bien et du mal, arrivée sous le règne de Louis $X V$, anuncia un relato en el que se mezclan la moral, la política, la poesía, la magia y el amor, en medio de una batalla que tuvo lugar en Francia, en tiempos de Luis XV, es decir el siglo XVIII. Ahora bien, durante el siglo XVIII los hombres de letras escribían desarrollando temas que también se discutían en los salones y las academias: filosóficos, políticos, religiosos, sociales. Los hombres de letras escribían tratados sobre cuestiones propuestas por las Academias, y en algunas ocasiones se atrevían a escribir novelas, a pesar de que hacerlo pudiera desprestigiarlos (Barguillet, 1981: 18-20). Sin embargo, estas ficciones son consideradas novelas filosóficas, es decir, textos cuya naturaleza narrativa los distingue de los tratados: en ellas, los personajes exponen las ideas o la filosofía del autor a través de las experiencias que viven y que relatan en la novela (Duflo, 2013: 9). La novela filosófica es, por lo tanto, un género apto para desarrollar los temas que inquietaban a un público deseoso de aprender y al mismo tiempo, deseoso de esparcimiento. Las ficciones jugaban una función similar a la de las cartas que los hombres de letras escribían para satisfacer a sus lectores que les solicitaban conocimientos, e incluso, de orientación para la vida (Delon, Mauzi y Menant, 1998: 31). Voltaire, Rousseau, Diderot, entre otros autores, promovieron la reflexión y la instrucción a través de un género donde era posible desarrollar prácticamente cualquier tema, sin olvidar las grandes preocupaciones filosóficas del siglo. Por esta razón, Le Crocodile de Saint-Martin puede ser considerada dentro del género de la novela filosófica, pues aborda el eterno tema de la lucha entre el bien y el mal, expuesto a través de la narración de acontecimientos vividos por los habitantes de París, previos a la Revolución francesa.

Después de haber escrito muchos textos que presentó a las Academias que convocaban a los filósofos y hombres de letras para debatir cuestiones como la del conocimiento humano, Louis-Claude de Saint-Martin se aventuró con Le Crocodile a escribir una obra de ficción. Si bien también había escrito versos y traducciones, así como mantenido una copiosa correspondencia, su público lector había sido el de los medios académicos, los philosophes y los gens de lettres. Con Le Crocodile, Saint-Martin se dirige a otros lectores, alejados del mundo intelectual pero interesados en aprender. Para llegar a ese público, el autor utiliza el esquema de la novela de ligas tan gustado en la literatura alemana, modelo en el cual se expone un misterio y una conspiración que rodean a un personaje inofensivo (Safranski, 2009: 53); el esquema permite a Saint-Martin presentar su propia visión de las fuerzas y los personajes causantes de los acontecimientos revolucionarios que transformaron a Francia. A través de la novela, el autor tiene la oportunidad de transmitir un mensaje trascendente: el hombre necesita volver al Origen, pero para conseguirlo, debe primero expandir su conciencia y buscar interiormente las respuestas a los problemas que lo agobian como individuo y como parte de la 
humanidad. Las ideas de Saint-Martin son ilustradas a través de los personajes y las peripecias que viven en la novela. Sédir, por ejemplo, en el bando de los buscadores de la verdad, es el hombre de deseo, quien se convierte en el discípulo del sabio Eléazar, al cual ayuda a enfrentar a los personajes malignos, enemigos que pretenden obstaculizar la tarea de velar por el Bien. Los Genios se encuentran en el bando de los aliados del Mal.

\section{Una novela esotérica o iluminista}

Hemos mencionado que Le Crocodile tuvo una acogida limitada, refiriéndonos a su aceptación, la cual se dio tan sólo en los sectores sensibles a su mensaje; para aquéllos que compartían la visión materialista y exclusivamente racionalista del mundo, la novela y su autor fueron incomprendidos e incluso despreciados (Matter, 1862: 336-337). La exploración en esta novela filosófica de Louis-Claude de Saint-Martin revela que, tal como lo refiere Paul Bénichou (1981), en ella son ridiculizadas las academias y sus miembros; sin embargo, también existen intenciones de registrar tradiciones e intrigas existentes en los grupos secretos en los que participó el autor. La novela es, por lo tanto, un relato por momentos autobiográfico, donde se entretejen las doctrinas y los grupos que marcaron las ideas del siglo XVIII. Albert Béguin (1991) señala que en los orígenes del romanticismo francés existe "una secreta tradición" que lo emparenta con el romanticismo alemán; el comentario sugiere que se refiere a la tradición iluminista o esotérica (Béguin, 1991), razón por la cual encontramos necesario conocer un poco más sobre el autor, su novela y el iluminismo. Debe decirse que no es fácil encontrar estudios sobre Le Crocodile, aunque sí existen investigaciones sobre la influencia de su autor en los escritores románticos.

Las ideas contenidas en la novela filosófica de Saint-Martin revelan huellas de pensamiento y espiritualidad que van más allá del catolicismo en el que fue educado como miembro de la aristocracia francesa. Aunque su nacimiento noble hizo posible que realizara estudios de Derecho, y después ingresar en la carrera de las armas, Louis-Claude de Saint-Martin abandonó ambas para seguir un camino propio. En el ambiente del ejército conoció a un personaje que lo introdujo en los grupos secretos de la francmasonería: Dom Martinez de Pasqually, judío converso cuya doctrina era una mezcla de ideas provenientes del judaísmo, el cristianismo y la Cábala. Más adelante, también conoció la doctrina del místico germano Jakob Böhme, quien también influyó grandemente en su pensamiento.

Es necesario recordar que no sólo la ciencia y la razón proveyeron de impulso al agitado siglo en que vivió, sino que la Ilustración, decidida a iluminar el mundo con la luz de la razón, invalidó otros tipos de conocimiento como la intuición y el sentimiento. Esto debe permitir entender mejor las aportaciones de Louis-Claude de Saint-Martin a las letras francesas, pues parece contradictorio que, compartiendo 
el ideal ilustrado de una humanidad liberada de la ignorancia que largamente había permitido la opresión de los pueblos, Saint-Martin sea considerado como un oponente de las Luces debido a su postura espiritualista. En este sentido, Le Crocodile afirma su oposición tanto al deísmo filosófico como al humanismo laico y filosófico (Bénichou, 1981: 84-101).

Como se había señalado arriba, es importante entender por qué nociones como las de iluminismo, esoterismo y teosofía se relacionan con Louis-Claude de SaintMartin y su defensa del espiritualismo: la biografía del autor revela que fue un teósofo, a la vez que un militante activo en grupos calificados de esotéricos. La noción de teosofía implica el conocimiento del mundo como una actividad de tipo trascendente, especulativa, pero interesada por la realidad suprasensible; a diferencia de la filosofía, caracterizada por su interés de conocer sobre todas las cosas del ámbito humano, la teosofía puede definirse también como un conocimiento que se adquiere libremente, "desde Dios hasta la naturaleza concreta", sin apegos a dogmas o instituciones, enfatizando puntos insuficientemente abordados por la doctrina pero que requieren de "la propia reflexión y la iluminación interior" (Faivre, 1976: 13-14). Ahora bien, dicha iluminación sobre Dios puede requerir de una disciplina, de una vida moderada y de ritos "[para] conseguir la visión íntima del principio de la realidad del mundo [... para lo cual se hacen útiles] la alquimia y la teúrgia, cualquiera de cuyos actos implica inseparablemente una concepción cosmogónica, cosmológica y escatológica" (Faivre, 1976: 15). Por lo tanto, la teosofía provee una idea del origen del universo, de su funcionamiento y las leyes que lo mueven, así como de su fin último. Reconocer a Saint-Martin como teósofo significa identificarlo por su interés y conocimiento de la naturaleza, sin apegarse a posiciones institucionales, ni religiosas ni académicas.

El Iluminismo, noción que hacia fines del siglo XIX adquirió el nombre de esoterismo, comprendía un saber poco conocido o sojuzgado sobre tradiciones religiosas y espirituales ancestrales. Sin embargo, el término esoterismo y sus temas han resultado del interés de la academia durante los siglos XX y XXI, y si bien existen visiones diferentes sobre su objeto de estudio y la metodología, los nombres de Antoine Faivre, François Secret y Henry Corbin, en Francia, aparecen junto a los de Robert McDermott, Christopher McIntosh, Joscelyn Godwin, Arthur Versluis, Kocku von Stuckrad y Wouter Hanegraaff en los ámbitos anglófono, germano y holandés. Al ser la metodología aportada por el pionero, Faivre (1994), la que ha sido generalmente aceptada, es la misma la que nos ha permitido iniciar una exploración de la novela filosófica de Louis-Claude de Saint-Martin.

Ante todo, Faivre acota su campo de estudio al esoterismo occidental, es decir, un estudio de las complejas interrelaciones entre corrientes y tradiciones:

from the early modern period up to the present day, the historical origin and foundations of which lies in the syncretistic phenomenon of Renaissance "hermeticism" [...] Western esotericism thus understood includes the so-called "occult philosophy" of the 
Renaissance and its later developments: Alchemy Paracelsianism and Rosicrucianism; Christian and post-Christian Kabbalah, Theosophical and Illuminist currents; and various occultist and related developments during the 19th and 20th century [...] it investigates a series of specific interrelated historical currents in modern and contemporary western culture, which have largely been neglected or disregarded by earlier generations. (Hanegraaff, 1999)

Hanegraaff coincide con Faivre al describir el esoterismo como una forma de pensamiento o conjunto de tendencias bien identificables con seis características resumibles así: a) Correspondencias, existentes entre las partes del universo visible $\mathrm{y}$ el invisible que deben leerse y descifrarse, pues todo en el universo es signo y todo alberga y manifiesta misterio. b) Naturaleza viviente, entendida como la presencia de fuerzas espirituales en el cosmos que conforma redes de afinidades y antipatías cuyo conocimiento permite restaurar un equilibrio original. Este supuesto justifica el uso de metales, plantas, gemas, sonidos, fluidos, etc., y a la vez, favoreció el desarrollo del paracelsismo, el magnetismo animal, la homeopatía. c) Imaginación y mediaciones, que posibilitan acceder desde las esferas inferiores hasta las superiores a través de rituales y símbolos, ello gracias a las correspondencias. Es gracias a la imaginación — como un órgano del alma — que se pueden establecer relaciones cognitivas y de visión con el mundo intermedio. La imaginación permite alcanzar dicho conocimiento o gnosis al ser instrumento de conocimiento del mundo, del mito; penetra las apariencias para realizar las conexiones y hacer visible lo invisible. d) Experiencia de transmutación, definible como un sendero iniciático de desarrollo que retoma las nociones alquímicas de transformación de la materia gracias a un conocimiento y ascesis que permite al practicante del esoterismo percibir los misterios del cosmos y realizar una purificación de su ser. e) Práctica de concordancia, que involucra la tendencia para reconocer lo común entre dos o más tradiciones diferentes, con la intención de alcanzar la iluminación o un conocimiento superior, la gnosis. f) Transmisión, que se refiere al flujo y comunicación de las enseñanzas esotéricas de maestro a discípulo en un esquema predefinido, donde la iniciación en los misterios y en las prácticas de una doctrina se realiza oral y directamente.

El término "esoterismo", en sus orígenes, se refería a un conocimiento oculto, accesible sólo para algunos iniciados en el mismo, opuesto a uno abierto a cualquiera. Sin embargo, actualmente se aplica más al estudio de una forma de pensamiento y de la historia de las ideas, así como del estudio de las religiones. Desde finales de los años 90 del siglo XX, el estudio del esoterismo se realiza considerando el rol tan importante que este pensamiento ha desarrollado en la historia cultural y religiosa de Europa, y muy significativo para la Modernidad (von Stuckrad, 2005). Para von Stuckrad, el campo de estudio se enfoca en la evolución de los discursos del esoterismo durante determinados contextos históricos; para académicos como Faivre, el esoterismo conlleva una desviación del cristianismo; 
para otros, las contribuciones realizadas por grupos como los de la francmasonería no son necesariamente vistas bajo una denominación religiosa. Así, el esoterismo provee maneras de interpretar procesos de la historia cultural de Europa (von Stuckrad, 2005). Para Antoine Faivre es necesario el uso del plural, pues no existe una sola forma de pensamiento, pero debe señalarse que el estudio del esoterismo occidental se refiere a una forma de pensamiento perceptible a través de tradiciones filosófico-espirituales presentes durante los primeros once siglos de nuestra era y que el Renacimiento, gracias a Pico della Mirandola y Marsilio Ficino, reunió con vistas a lograr un conjunto homogéneo (Faivre, 1994: 7).

El saber de estas tradiciones llega a nuestros tiempos transformándose en la idea de un conocimiento único sobre Dios presente en todas las religiones. Desde el Medioevo hasta la Edad Moderna, dicha transformación permitió cada vez una mayor autonomía de la teología, estableciendo enlaces entre los mitos de diferentes tradiciones religiosas para constituirse en una sola cadena en la que se busca reconocer el imaginario presente en ellas en diferentes momentos. En el siglo XVI se produce la separación entre la religión oficial, la teología y las tradiciones antiguas; por un lado quedaron la teología y la religión oficial marginalizando a las tradiciones no europeas y a las anteriores al cristianismo; en el otro, el proyecto renacentista de hallar puntos de contacto entre las diferentes tradiciones permitió el surgimiento de lo que hoy se conoce como esoterismo, es decir, un conocimiento autónomo, impulsado por los humanistas, basado en la investigación y reflexión sobre aspectos soslayados por la enseñanza oficial.

En aquel tiempo en el que las ciencias modernas no habían encontrado su autonomía y dependían aún de la metafísica, el proyecto de los humanistas renacentistas pretendía conectar los campos teológico-religioso con el cosmológico. Más adelante, al emanciparse del campo metafísico, el estudio del universo conformó su propio ámbito de conocimiento empírico; igualmente, el esoterismo elaboró el suyo y paulatinamente se sumaron a este último otras disciplinas con una larga presencia histórica: la alquimia, la astrología y la magia, así como la aritmosofía —o la ciencia de los números - y otras corrientes con orígenes diversos hasta llegar al tiempo presente. La supervivencia de las corrientes y tradiciones aún después del Renacimiento, aunada al quiebre del racionalismo en el siglo XVII y su pervivencia hasta nuestro tiempo, se explica como una forma de balancear dos componentes del alma humana; por un lado, la visión científica y secularizada del mundo, y por el otro, la capacidad mítica (Faivre, 1994: 9).

Dicho lo anterior, puede considerarse también que, siendo una novela filosófica, Le Crocodile de Louis-Claude de Saint-Martin es también una novela esotérica, pues en ella se encuentran los seis elementos del pensamiento esotérico reconocidos por Faivre, los cuales son expuestos a través de los personajes y del narrador de la novela.

Recordemos que la novela relata la historia de la guerra del Bien contra el Mal, y cuyos personajes principales se alían a una u otra postura. Al Bien se adhiere 
Eléazar, líder y hombre sabio, heredero de un conocimiento ancestral que pone al servicio del Bien y que transmite a sus seguidores. Sédir es el discípulo principal de Eléazar, quien representa al hombre de deseo, el que aspira al conocimiento trascendente. Ourdeck es un admirador de la Ilustración y defiende sus valores contra el Antiguo orden. Madame Jof es el personaje alegórico que guía a la Sociedad de los Independientes, es decir, a los hombres conscientes y que buscan tanto el conocimiento trascendente, como una sociedad mejor, pero sin ataduras institucionales. Looker es el hombre con una inteligencia que le permite ver más allá de lo sensible y que anuncia los tiempos difíciles para Francia y los parisinos. En el lado contrario, los personajes malignos están encabezados por el Cocodrilo, personaje alegórico ligado al caos, la guerra y el mundo de la materia. También se encuentran una serie de Genios: el de Mercurio, el de Etiopía, los cuales representan y ayudan al Genio de Saturno, que es el señor de la materia universal, el que rige el tiempo. Otros personajes conspiradores contra el Bien son una mujer gorda, un hombre delgado, un hombre egipcio y, finalmente, Roson, el discípulo descarriado de Eléazar, quien abandona las enseñanzas de su maestro y cuya inconciencia lo hace susceptible de abandonarse a las pasiones.

Ahora referiremos el pensamiento esotérico en Le Crocodile, sin olvidar que los eventos y los personajes en una novela filosófica son los transmisores de las ideas del autor. Como sabio conocedor de las tradiciones ancestrales, Eléazar es capaz de iniciar en un conocimiento superior a hombres como Sédir, enseñándoles los secretos que sabios árabes le transmitieron, como la cuidadosa fabricación de una sal que permitía a quien se le administrara tener visiones para conocer sobre cualquier evento o persona independientemente del lugar en el que se encuentre. A lo largo de su iniciación, Sédir aprende que el conocimiento total de los seres y las leyes que mueven al universo se encuentra dentro de cada ser humano y que para descubrirlo sólo basta con observar la naturaleza y encontrar en ella la cercanía con la fuente superior del Origen. También la imaginación juega un papel en la obtención del conocimiento de lo superior; gracias a ella, Sédir aprende sobre realidades ocurridas en otros lugares y tiempos, convirtiéndose en testigo a distancia de las reuniones que sostienen los conspiradores del Mal y, también, es capaz de "ver" y entender el recorrido de Ourdeck dentro del Cocodrilo como un viaje de conocimiento sobre la historia y la condición de la humanidad.

En cuanto a la iniciación, las correspondencias, las mediaciones, en el Canto 46 de la novela, la iniciación de Sédir en la doctrina de Eléazar se realiza a través de un estado de trance favorecido por el uso de las sales que el maestro le administra al discípulo. Eléazar conoce las correspondencias entre elementos naturales — plantas, minerales - y su efecto, siempre que existe una disposición psíquica favorable para recibir enseñanzas difícilmente accesibles de otro modo. Para la iniciación, es decir la entrada al círculo de los miembros del grupo esotérico, existe un proceso y reglas que el discípulo debe respetar, como por ejemplo la obligación de mantener secretas ciertas cosas. Para Saint-Martin, así como para 
el abad Fournié — también discípulo de Martinez de Pasqually — este mandamiento era observado celosamente, al grado que Fournié se abstuvo de escribir más sobre la doctrina de su maestro, convencido de que cierto conocimiento debía ser reservado. Igualmente, Saint-Martin se mostraba discreto al ser consultado sobre los ritos de invocación de las fuerzas de intermediación que permitieran al hombre acercarse a Dios. Nuestro autor creía que la superioridad de lo divino dificultaba entablar una comunicación directa entre Dios y el hombre; y, por encontrarse en esferas de existencia muy diferentes, las intermediaciones eran necesarias, pero sólo hasta que estuviera completado el plan de reintegración del hombre a su origen divino. Por lo tanto, Saint-Martin prevenía sobre la necesidad de limitar dichos contactos con los seres intermedios, con la finalidad de evitar la contaminación energética perniciosa que seres extraños a la esfera humana pudieran provocar en el hombre.

En el canto 68 de Le Crocodile se advierte contra el uso equivocado del conocimiento y los rituales practicados por ciertos personajes y grupos oscuros, puesto que el cuerpo humano no está formado únicamente por órganos y sistemas, sino también por pensamientos - cuyo origen no es distinguible materialmente-; así se explica que las ceremonias desencadenen fuerzas desconocidas que pueden producir enfermedad y que, por lo tanto, no deben ser liberadas. Además, SaintMartin cuestionaba la recurrencia exclusiva o excesiva a los ritos porque banalizaban el camino hacia el desarrollo espiritual. De este modo, en diferentes cantos de la novela se encuentran personajes manifestando lo anterior, por ejemplo, en los que se alerta sobre la manipulación que en ciertos grupos ocultistas se ejercía sobre los seguidores con promesas y amenazas, pero también distrayéndolos de lo verdaderamente importante, el perfeccionamiento individual y trascendente. En el canto 48, un personaje se lamenta por haberse involucrado demasiado en dichas ceremonias: "Au lieu de la paix qu'ils m'avoient promise, je n'ai eu que du trouble $[\ldots]$ au lieu des lumières [...] je n'ai qu'une incertitude universelle" (Saint-Martin, 1799). Así, este canto también expresa la desconfianza de Saint-Martin hacia los ritos y ceremonias realizados en algunos grupos ocultistas, no sólo por el riesgo de perderse en la esfera intranscendente de la materia, sino también porque dichas prácticas excesivas prometían un camino fácil para el hombre y la consecución de sus deseos inmediatos; para Saint-Martin, el camino liberador que llevaría a los hombres de vuelta con Dios es un camino que demanda esfuerzo, voluntad, contemplación, la oración y por supuesto, la razón como guías para discernir lo falso de lo verdadero. El espiritualismo de Saint-Martin y su pensamiento esotérico no planteaban un escape o un abandono del hombre hacia lo irracional como podría considerarlo la filosofía intelectualista de los philosophes, así como tampoco proponía la descalificación de la razón. Para él, el valor de ésta no consiste en una capacidad única y absoluta para conocer - como lo propone el racionalismo - . En cambio, Saint-Martin pretende rescatarla como un instrumento para trascender la realidad. 
Saint-Martin, como Böhme, no consideraba la materia como un principio negativo en sí mismo, pues es necesaria para poder manifestar la esencia divina (Faivre, 1976: 57); debido a ello, el hombre no debería sentirse superior a la naturaleza ni debería querer someterla - como cierta visión mecanicista de la ciencia - sino entenderla como reflejo de la vida, así como el hombre es un reflejo de Dios. Esta noción de la naturaleza y el hombre en comunión como parte del Todo es recurrente en los poetas románticos, como Lamartine, cuya poesía expresa la intimidad que guarda el hombre con los lagos, las montañas, el viento. El pensamiento esotérico busca hacer comprensible y armónico lo heterogéneo; explicar la coexistencia de los opuestos, gracias a las analogías; conocer a Dios a través del conocimiento del mundo y del entendimiento de que el hombre es un universo en pequeño, en constante correspondencia y relación armónica con el cosmos: "tout est individuel, et cependant tout n'est qu'un. Quel est donc cet être immense qui de son centre impénétrable voit tous les êtres, les astres, l'univers entier ne former qu'un point de son incommensurable sphère" (Saint-Martin, 2002). Las correspondencias y la estrecha relación entre el hombre y el cielo se ilustran en el Canto 1 de la novela, donde la voz del poeta refiere el sufrimiento de los astros que presienten los males que se avecinan en la Tierra: "Depuis plusieurs mois on voyoit des signes extraordinaires dans le ciel [...] la lune avoit poussé des gémissemens comme si elle eût été en travail [...] Tous les astres à la fois paroissoient donner des signes de tristesse" (Saint-Martin, 1799).

La transmisión de una enseñanza es visible en los roles que juegan los personajes Madame Jof y Eléazar, pues ambos transmiten una gnosis de manera directa y personal a sus discípulos elegidos, Sédir y Ourdeck. El viaje fantástico de Ourdeck por el interior del Cocodrilo, en el canto 15 de la novela, le revela un saber comprensible sólo por unos cuantos. Los miembros de la Sociedad de los Independientes, por su parte, aprenden las reglas de la transmisión de la doctrina de Madame Jof: la verdad debe ser comunicada con reserva, y en clave, para evitar un mal uso de la misma. Esta manera de transmitir un saber de forma restringida corresponde a una lógica del ocultamiento que Georg Simmel estudió en el ámbito de la vida social (Simmel, 2015). Para Simmel, el secreto es un mecanismo de protección para los miembros de grupos que buscan mantenerse encubiertos y les permite resguardar información que sólo les concierne a ellos. Sin embargo, esta lógica también apoya las diferencias y las jerarquías al interior de los grupos, cuyo objetivo es diferenciar la aptitud y el proceso de los miembros, pues el conocimiento alcanzado por algunos no es compartible con aquéllos a quienes falta preparación para asimilarlo. El miembro más preparado, su líder, dosifica la transmisión del conocimiento que posee, a través de una instrucción de forma oral, posibilitando resguardar el mensaje y también que el discípulo aprenda según el nivel de profundidad y desarrollo que ha adquirido. Dicho de otro modo, el misterio es un mecanismo que facilita la conformación de grupos de individuos con intereses semejantes que quieren diferenciarse del grupo social mayor al que pertenecen. 
Así se comprende la tendencia de las asociaciones esotéricas de mantenerse en el ocultamiento, para preservar ideas que los unen y los distinguen dentro de una comunidad más amplia.

Lo expresado arriba viene al caso para señalar, tanto en la novela como en la biografía de Saint-Martin, el valor del secreto, que, llevado al extremo, se convierte en silencio y constituye, según Simmel, un ejercicio disciplinario dentro de los grupos secretos como la francmasonería. Tanto Looker como Madame Jof expresan la necesidad de cuidar la transmisión de su saber. El primero alega la enemistad natural existente entre los ingleses y los franceses, mientras que Madame Jof advierte que sólo algunos hombres están preparados para conocer ciertas cosas. A pesar de que el conocimiento de la Verdad es para todos, el acceso a él debe ser progresivo, conforme se ha alcanzado el grado de conciencia necesario. También, durante el viaje de Ourdeck, en el canto 71, el viajero ve a un sabio haciendo un gesto con el dedo sobre su boca, poniendo de relieve el valor del silencio para realizar un aprendizaje que involucre profundamente al discípulo.

Ahora bien, ya informamos arriba que en la experiencia de Louis-Claude de Saint-Martin la transmisión de la doctrina de su maestro, Martinez de Pasqually, era reservada: sólo la transmitió a los discípulos más cercanos y capaces de entenderla, ya que implicaban una doctrina compleja. Matter calificó a este judío converso como un teúrgo, es decir, un practicante de rituales con los que pretende conseguir un contacto con entidades metafísicas. Martinez inició a Saint-Martin en una tradición de su propia creación que marcaría profundamente al Filósofo desconocido, tradición misteriosa que plasmó en el Traité sur la réintégration des êtres dans leurs premières propriétés, vertus et puissances spirituelles et divines, y en la cual propone "el restablecimiento del hombre y de todos los seres a su estado primordial" (Matter, 1862: 12). La doctrina de Martinez de Pasqually contiene una importante noción: la "Caída del hombre" de la gracia divina, es decir, su existencia en un cuerpo físico que es el causante de sus males. Dichas ideas solamente han podido ser parcialmente conocidas a través del mencionado tratado y de algunas cartas dirigidas a sus discípulos más cercanos en las que les daba instrucciones sobre ritos. En la experiencia de Louis-Claude de Saint-Martin con su maestro tenían lugar ceremonias tendientes al restablecimiento del orden en la creación divina. En ellas se pedía la intercesión de entidades no humanas a las que había de agradar con actos profesados por la comunidad reunida. No obstante, Saint-Martin, más dispuesto a una espiritualidad interior, no comulgaba completamente con estas prácticas y cuestionaba a su maestro sobre la validez de tantos ritos para acercarse a Dios (Matter, 1862: 21).

Ya expresamos arriba que Saint-Martin considera útiles los ritos y las mediaciones en la medida que preparen al practicante para una mejor disposición de contacto con Dios, para ayudar al hombre a recobrar la unidad original. Lo anterior es importante pues, si bien Louis-Claude de Saint-Martin mantuvo la convicción sobre la existencia de seres superiores, intermediarios entre el mundo humano y el 
divino, él valoraba más el contacto íntimo con Dios, contacto que le parecía debería darse desapegado de las formas y de los rituales. Su disposición espiritual es hacia la Iglesia interior, es decir, una búsqueda de la unión con lo divino sin necesidad de un templo, ni una institución, ni complejas ceremonias (Faivre, 1994).

Hemos dicho que Louis-Claude de Saint-Martin no era un partidario absoluto de los ritos; que sin embargo, se inició en ellos por su maestro Martinez de Pasqually y que la espiritualidad de Böhme lo sostuvo en la convicción de que el contacto con Dios es algo íntimo y personal. Pero no es posible afirmar que Saint-Martin haya abandonado por completo dichas prácticas de mediación, puesto que reconocía su utilidad en el proceso de acceder a la iluminación. Su iniciación en la francmasonería lo puso en contacto con grupos esotéricos del siglo XVIII, y su pertenencia a la misma de ninguna forma contradecía su interés por el estudio de la naturaleza y las cosas de Dios. Por el contrario, su ideal de contribuir a crear una sociedad más cercana a la perfección original, así como su convicción de logarlo a partir de una búsqueda interior, ajena a templos o Iglesias, encontró resonancia en la búsqueda y el apoyo de hombres y mujeres que se unían en aquellos tiempos a diferentes sociedades con las mismas aspiraciones. Los grupos francmasones en los que participó resultaron ser los grupos que le permitieron en alguna medida realizar la experiencia de transmutación, es decir, una experiencia de transformación de un hombre ordinario en el ser superior llamado a reintegrarse con lo divino. En ellos, SaintMartin pudo tener contacto con el conocimiento para acercarlo a la gnosis, es decir, el conocimiento espiritual necesario para dicha transformación.

Del mismo modo, en Le Crocodile, personajes como Sédir o como Ourdeck realizan la búsqueda constante del Bien, guiados por Madame Jof, la Fe, y logran reunirse en torno a un grupo de hombres y mujeres deseosos como ellos de una sociedad perfecta. A ellos les es posible realizar la transformación, dado que tras ser iniciados por el maestro Eléazar, siguen y respetan sus enseñanzas; esto no sucede con Roson, quien también fue su discípulo pero no logró superar su inclinación por las pasiones; experimenta la aventura, la fortuna, la miseria y la opulencia sin encontrarse nunca satisfecho, hasta que se convierte en líder de las revueltas en París. Roson es el hombre inconsciente que vive la vida con excesos, sin aspiraciones espirituales. El caso de Ourdeck es el del hombre animado por la razón: su ideal es la filosofía ilustrada como arma para liberar a los hombres del oscurantismo. Pero Ourdeck sólo acepta el conocimiento del intelecto y tendrá que vivir un viaje iniciático, guiado por Madame Jof, para alcanzar un conocimiento complementario y necesario. Ourdeck es tragado, junto con el ejército de las fuerzas del Bien, por el Cocodrilo, y así le es dado conocer la historia de la humanidad (Saint-Martin, 1799: cantos 54-59). Tras ese viaje de iniciación, Ourdeck deja de ser el hombre guiado únicamente por la razón y se convierte en un aliado de Eléazar y de Sédir. En cuanto a Sédir, el personaje representa al discípulo perfecto que ha logrado transmutar al hombre ordinario en un hombre consciente que busca el bien propio y el de los hombres para alcanzar el plan divino. 
Louis-Claude de Saint-Martin entendía el conocimiento humano a través de una visión teosófica, por lo que a él le parecía que la ciencia del siglo XVIII se había alejado de la misión trascendente como verdadera guía de los hombres. La ciencia debería dejar de privilegiar un conocimiento medible, basado exclusivamente en la experiencia sensible, y tendría que reconectar al hombre con la naturaleza y el cosmos para lograr un verdadero entendimiento de ambos. Dicha misión no era posible, para Saint-Martin, con la postura descalificadora de las Academias ni con una filosofía que rechazara abrirse al rescate de la tradición y a la aceptación del misterio; la postura del Filósofo desconocido no pretendía abrir la puerta de regreso a la enajenación de los hombres, sino entender la experiencia humana a través de cuanto existe en el cosmos, a través del estudio de todos sus elementos y de la interpretación de todos sus signos. Por esta razón, el ideal de la ciencia, para Saint-Martin, debería de integrar en sus métodos de conocimiento leyes como la de la analogía y las correspondencias, aunque las mismas perdían significado para los hombres de ciencia, más interesados en una ciencia de análisis. Entendemos así el que Paul Bénichou (1981) califique Le Crocodile como una sátira contra el academicismo, y entendemos que está inspirada en la rebeldía que su autor compartía efectivamente con más hombres que, en ese siglo XVIII, rechazaban la monopolización del saber científico tanto como la del poder político (Darnton, 1968). Louis-Claude de Saint-Martin tomó parte principal en ese enfrentamiento de dos visiones opuestas de la realidad tras la cual se gestaba la revolución romántica.

Señalábamos arriba que los hombres que como Saint-Martin rechazaban someter la ciencia y el conocimiento a un puro ejercicio formal o mecánico encontraron en diferentes grupos el espacio para reunirse y empujar juntos su propia visión. En la novela, la Sociedad de los Independientes se mantiene unida sin necesidad de reuniones físicas y sin necesidad de someterse a una autoridad impuesta, ya que cada uno de ellos comparte la misma voluntad de trabajar por su propio bien espiritual que permitirá crear una Iglesia invisible (Faivre, 1976: 3839). En palabras más accesibles, la noción de Iglesia invisible se refiere a que en una sociedad el bien de cada uno debe apoyar el bienestar de los otros, y por lo tanto hace innecesarios los gobiernos conocidos como hasta entonces. En la biografía de Saint-Martin, su pertenencia a los grupos francmasones fue posible porque al interior de ellos la adherencia a una religión institucionalizada no constituía un requisito: en ellos convivían tanto católicos como protestantes, e incluso hombres sin una fe particular. Lo que unía a todos era el deseo de encontrarse con hombres de la misma condición: libres y dispuestos a mejorar como individuos y a aportar lo mejor al mundo, a la paz, a la construcción de relaciones sociales más armónicas. Su aportación estaba marcada tanto por el interés científico como por el místico, tal como lo revelan los estudios sobre la francmasonería europea (Beaurepaire, 2018: 69-169). El estrecho contacto que Saint-Martin mantuvo con la francmasonería se explica por el hecho de que dicha sociedad se transformó a 
partir del siglo XVIII en algo más que una cofradía de trabajadores de la construcción. La francmasonería en el siglo XVIII promueve la idea, tal como lo habían establecido las Constituciones de Anderson de 1723, de una espiritualidad individual que reúne a los miembros en una comunidad de hombres libres y abiertos a todas las formas de pensamiento para favorecer un progreso moral y científico de la humanidad (Beaurepaire, 2018: 15-67). La inclinación de Saint-Martin a creer en la constitución de una Iglesia interior lo acerca al sobrio misticismo de Jakob Böhme: éste provee a la formación católica de nuestro autor una profundidad que los complejos ritos ocultistas de Martinez de Pasqually no le podían aportar. Esto parece un signo del rechazo expresado por Louis-Claude de Saint-Martin contra lo que considera un conocimiento banal buscado por la ciencia de su tiempo, enfocada en una visión cuantificable y materialista del mundo.

Citamos dos ejemplos que ilustran en la novela el choque que tiene lugar en el siglo XVIII entre dos formas de conocimiento. El primero es el personaje de John Looker, quien expresa en su manuscrito cómo es malentendido y juzgado fantasioso e ingenuo porque confía en un conocimiento no racional, esto a propósito de las visiones que tiene y que le anuncian tiempos de sufrimiento para Francia. El otro caso se encuentra en los discursos de Madame Jof, quien rechaza los métodos de conocimiento de la ciencia del siglo:

Un torrent de prestiges a inondé l'intelligence humaine en général [...] parce que [Paris] renferme des savans et des docteurs de tout genre [mais] possède bien peu qui tournent leurs pensées vers la recherche des véritables connoissances [et] avec un véritable esprit [...] La plupart d'entr'eux ne s'attachent qu'à disséquer l'écorce de la nature, à en mesurer, peser et nombrer toutes les molécules, et tentent, en insensés, la conquête fixe et complète de tout ce qui entre dans la composition de l'univers; comme si cela leur étoit possible, à la manière dont ils s'y prennent! [...] ils ne s'empareront jamais du secret de son existence. (Saint-Martin, 1799: canto 15)

Puede pensarse que Louis-Claude de Saint-Martin era partidario de un regreso al oscurantismo vivido en Europa durante muchos siglos, mientras el poder y el conocimiento fueron monopolizados por la Iglesia y los gobiernos. De ese monopolio, precisamente, Saint-Martin piensa que debe liberarse a los hombres, pero ni las academias ni los poderes temporales o espirituales favorecían esa emancipación invalidando otras formas de conocimiento e imponiendo a la ciencia la frialdad del análisis. Los cantos 41 a 44 de Le Crocodile mueven a reflexionar sobre los métodos y la autoridad de las ciencias: una plaga azota las bibliotecas de París y todo el saber que reúnen se convierte en polvo, mientras los estudiosos no pueden encontrar la razón, y los sabios son ridiculizados al ser presentados como niños pequeños alimentados con una papilla obtenida del polvo producido por la plaga. Saint-Martin considera que los académicos y los hombres letrados de aquel tiempo se han dejado imponer los criterios de las academias para ejercer las ciencias, recibiendo y repitiendo discursos que no son producto de una práctica y reflexión 
interior. El teósofo no era un enemigo de las ciencias; por el contrario, quienes lo conocieron describieron en él a un hombre interesado por el progreso científico. Sin embargo, lo consideraban también un hombre que creía en la misión de las ciencias de desarrollar un conocimiento integral del mundo, un conocimiento que considerara el aspecto metafísico. Muestra de su interés por conocer fue el abundante intercambio epistolar que Louis-Claude de Saint-Martin sostuvo con hombres de ciencia, los cuales integraban los círculos francmasones de aquellos años.

Para terminar, resaltaremos aspectos importantes que podrían pasar inadvertidos al leer Le Crocodile. En esta novela filosófica existe ciertamente la intención explícita del autor de contar una historia sobre el enfrentamiento del Bien contra el Mal; sin embargo, sus intenciones no se limitaron a mostrar una guerra entre posturas académicas o espirituales. Existen claves en la novela que permiten afirmar que dicha guerra existió en otras esferas, como la del poder político, particularmente en el seno de las logias francmasonas. El referente histórico de las luchas vividas por la francmasonería se encuentra relacionado con otros poderes de aquel tiempo, como la enemistad de la Iglesia católica romana y los gobiernos ingleses. En la historia de la francmasonería han existido diferencias entre las logias, siendo la más antigua la que opuso a las logias anglosajonas de los Antiguos y la de los Modernos, defendiendo cada una su postura en torno a los rituales y las ceremonias. Los Modernos estaban ligados a la fundación de la Gran Logia de Londres en 1717, y habían simplificado los rituales a tal grado que los Antiguos, de origen escocés, defendieron en 1751 las tradiciones y ceremonias que los identificaban con el catolicismo de sus orígenes. Es oportuno recordar aquí que John Looker, el personaje que vaticina la guerra en París, también alude en su manuscrito a los genios que defienden los intereses de los ingleses, lo cual podría tener relación con las tensiones vividas en las logias anglosajonas motivadas por la defensa o la oposición a la práctica ritualista que mencionamos más arriba. Alec Mellor (2005: Préface) sugiere que tras la fuerza que cobró la Royal Society se escondían los intereses de los Modernos, ligados a intereses y prerrogativas políticas y económicas a favor de Inglaterra.

En cuanto a las logias francesas, su historia parece remontar a Escocia, con orígenes en las logias católicas de ese reino y en relación con un personaje controvertido: André Michel de Ramsay (1686-1743), quien creo el mito fundacional de la francmasonería como heredera de la Orden del Temple y las Cruzadas. De ese mito parece desprenderse toda una serie de misterios en torno a este grupo secreto $\mathrm{y}$, por supuesto, una abundante producción editorial que continúa hasta nuestros días (Mercier, 2017: 353-404). Habíamos anotado más arriba que el interés común de los hombres organizados alrededor de las logias era velar por la construcción de una sociedad más armónica; sin embargo, la historia de las relaciones que se construyeron en ese afán también ha revelado que existían diferencias entre ellas y que parecen explicarse por el tipo de inspiración que las motivaba, así como la defensa 
de su autonomía política y religiosa. Aunque esquemáticamente, puede decirse que por un lado se encontraban las logias de inclinaciones místicas, cercanas al catolicismo; las logias de ascendencia británica estaban, como puede suponerse, más inclinadas al racionalismo y, por supuesto, desconfiaban de cuanto tuviera tintes de catolicismo y nexos con la Compañía de Jesús. Tampoco las logias germanas fueron ajenas a las disputas de intereses que ya mencionamos, pero en 1782 tuvo lugar una batalla a la que seguramente evoca veladamente Le Crocodile. Se reunieron en Wilhelmsbad las logias europeas con el fin de puntualizar temas como el origen y los fines de la francmasonería, pero en dicha convención se comprobó que en el fondo existían profundas luchas de poder entre grupos nacionalistas y grupos con intereses filosófico-religiosos. Antoine Faivre explica esto como el enfrentamiento entre el protestantismo aliado con la postura racionalista de las logias alemanas de ascendencia británica, y en el otro frente, el espiritualismo identificado con el catolicismo y con los jesuitas (Faivre, 1976: 179). No faltaron tampoco las organizaciones que falsamente se calificaban de francmasonas, cuando en realidad sólo utilizaban los símbolos y los rituales para enmascarar movimientos políticos revolucionarios, como fue el caso de los Iluminados de Baviera.

Aunque lo poco que hasta aquí hemos apuntado es ejemplo de la complejidad de la escritura de Louis-Claude de Saint-Martin a través de esta novela filosófica, sin duda queda aún bastante por estudiar a propósito de los referentes que dieron origen a Le Crocodile. Más que valorar su perfección formal o demeritarla, es evidente que en ella es válido rastrear esa historia tan poco estudiada del Siglo de las Luces, la que tiene que ver con sus aspectos menos luminosos, los más secretos y tal vez, los que permitan comprender mejor toda su riqueza.

\section{Referencias bibliográficas}

BARguILLET, Françoise. (1981). Le Roman au XVIIIe siècle. París: PUF.

BeAurePAIRE, Pierre-Yves. (2018 [2002]). L'Europe des franc-maçons. XVIIIeXXIe siècles. París: Belin, Humensis.

BÉGUIN, Albert. (1991 [1937]). L'âme romantique et le rêve. Essai sur le romantisme allemand et la poésie française. París: José Corti.

BÉnICHOU, Paul. (1981 [1973]). "Iluminismo y poesía. Louis-Claude de SaintMartin". En La Coronación del escritor. Ensayo sobre el advenimiento de un poder espiritual laico en la Francia moderna (Aurelio Garzón del Camino, Trad.). México: FCE. 84-101.

DARNTON, Robert. (1968). Mesmerism and the End of the Enlightenment in France. Cambridge: Harvard University Press.

Delon, Michel; Mauzi, Robert; y Menant, Sylvain. (1998). Histoire de la littérature française. De l'Encyclopédie aux Méditations. París: GF Flammarion. 
Duflo, Colas. (2013). Les Aventures de Sophie. La philosophie dans le roman au XVIIIe siècle. París: CNRS Éditions.

FAIVRE, Antoine. (1976 [1973]). El Esoterismo en el siglo XVIII (Jesús Florentino Díaz Prieto, Trad.). Madrid: EDAF.

FAIVRE, Antoine. (1994). Access to Western Esotericism. Albany: State University of New York Press.

HANEGRAAFF, Wouter J. (1995). "Empirical Method in the Study of Esotericism". Method \& Theory in the Study of Religion, 7(2), 99-129.

HANEGRAAFF, Wouter J. (1999). "Some Remarks on the Study of Western Esotericism". Theosophical History, 223-232. Recuperado de http://esoteric.msu. edu/Hanegraaff.html

Matter, M. (1862). Saint-Martin. Le philosophe inconnu, sa vie et ses écrits, son maître Martinez et leurs groupes d'aprés des documents inédits. París: Librairie Académique Didier et Cie., Libraires Éditeurs.

MELLOR, Alec. (2005). Dictionnaire de la franc-maçonnerie et des francs-maçons. París: Belfond.

MERCIER, Jean-Marie. (2017). La fabrique de la franc-maçonnerie française. Histoire, sociabilité et rituels. 1725-1750. París: Dervy.

SAFRANSKI, Rudiger. (2009 [2007]). Romanticismo. Una odisea del espíritu alemán. En Raúl Gabás (trad.). México: Tusquets Editores.

SAINT-MARTIN, Louis-Claude de. (1799). Le Crocodile, ou la Guerre du Bien et du Mal. París: De l'Imprimerie-Librairie du Cercle Social, l'an VII [de la République].

SAINT-MarTin, Louis-Claude de. (2002 [1790]). L'homme de désir. Ginebra: Arbre d'Or. Recuperado el 20 de enero de 2020 de http://www.arbredor.com/ ebooks/HommeDesir.pdf

VON StUCKRAD, Koku. (2005). Western Esotericism. A Brief History of Secret Knowledge. Londres: Equinox Publishing Ltd. 